\title{
POSSIBILIDADE DE UMA HERMENÊUTICA DO SI MESMO SEGUNDO PAUL RICOUER PARA O ENSINO DE FILOSOFIA NO ENSINO MÉDIO
}

\section{POSSIBILITY OF A HERMENEUTICS OF THE SAME SECOND PAUL RICOEUR FOR THE TEACHING OF PHILOSOPHY IN MIDDLE SCHOOL}

\author{
Fagner Veloso da Silva \\ Ricardo Leon Lopes ${ }^{2}$
}

Recebido em: 05/2018

Aprovado em: 07/2018

\begin{abstract}
Resumo: O ensino e a aprendizagem da filosofia constituem dois momentos importantes do exercício e da atividade filosófica na sala de aula, pois através desta atividade buscar-se-á criar, inventar, reinventar e produzir novos saberes e ações que se configurem como uma experiência filosófica. A experiência do filosofar possibilita uma maior flexibilidade entre o pensar e o agir, tendo como finalidade a constituição do si do alunado. Mediante a experiência do filosofar entendemos não apenas a reflexão, a compreensão e interpretação dos textos filosóficos, mas uma auto interpretação que o sujeito assume por sua educação, identidade/constituição de si. Por suas deliberações e avaliações de suas ações, o aluno caminha para aquilo que Paul Ricoeur chamou de "a visada da vida boa com e para outrem em instituições justas". E, para alcançar essa "vida boa com e para outrem em instituições justas" parece necessário a capacidade de ordenar e reconstruir suas experiências de vida. Para alcance desse objetivo o sujeito tem de interpretar o seu próprio eu, pois o ser humano busca não só fazer uma descrição de sua existência no mundo, ele quer interpretar o sentido desta sua existência, razão pela qual possui uma necessidade de compreender o seu ser mundo. Realizando esse esforço reflexivo para uma tomada da consciência de si, os alunos podem adquirir novos sentidos e valores que o permitam viver numa perspectiva ética que eles mesmos poderão escolher entre a que entender ser mais adequada para sua vida, possibilitando-os desenvolver seus projetos pessoais e sociais com responsabilidade diante de seu próprio agir. Por esta razão buscamos delinear os traços de uma hermenêutica filosófica que proporcionasse não apenas regras de interpretação textual, mas de uma compreensão que possa auxiliar a existência humana tendo como fundamento a criação de parâmetros filosóficos para os alunos criarem e re-criarem a si mesmo e ao mundo de forma original e autônoma.
\end{abstract}

Palavras-chave: Constituição do si. Experiência. Filosofar. Hermenêutica.

\begin{abstract}
The teaching and learning of philosophy are two important moments of the exercise and philosophical activity in the classroom, because through this activity we will seek to create, invent, reinvent and produce new knowledge and actions that are configured as a philosophical experience. The experience of philosophizing allows for greater flexibility between thinking and acting, aiming at the constitution of the student's self. Through the experience of philosophizing we understand not only the reflection, the understanding and interpretation of philosophical texts, but a self-interpretation that the subject assumes by his education, identity / constitution of
\end{abstract}

\footnotetext{
${ }^{1}$ Universidade Federal de Campina Grande. Email: fagner_rian@ @otmail.com

${ }^{2}$ Pós-Doutorado em Filosofia Antiga pela Universidad de Salamanca, Espanha. Ele está vinculado ao Mestrado Profissional em Filosofia (PROF-FILO), núcleo UFCG. Email: ricardoleon@uol.com.br
} 
himself. Through his deliberations and evaluations of his actions, the student moves to what Paul Ricoeur called "the aim of the good life with and for others in just institutions". And to achieve this "good life with and for others in just institutions" it seems necessary the ability to order and rebuild their life experiences. To achieve this goal the subject has to interpret his own self, because the human being seeks not only to make a description of his existence in the world, he wants to interpret the meaning of his existence, which is why he has a need to understand his being world. By making this reflexive effort to take self-awareness, students can acquire new meanings and values that allow them to live in an ethical perspective that they themselves can choose between what they think is more appropriate for their life, enabling them to develop their personal projects and social responsibility with regard to their own actions. For this reason we seek to delineate the traces of a philosophical hermeneutics that provides not only rules of textual interpretation, but an understanding that can aid human existence on the basis of the creation of philosophical parameters for students to create and re-create themselves and to the world in an original and autonomous way.

Keywords: Constitution of the self. Experience. Philosophize. Hermeneutics.

\section{Prática de ensino que favoreça um diálogo entre os textos filosóficos e os estudantes}

A Lei de Diretrizes e Bases da educação brasileira em seu Art. $1^{\circ}$ afirma que a educação se estende a processos formativos que são desenvolvidos "na vida familiar, na convivência humana, no trabalho, nas instituições de ensino e pesquisa, nos movimentos sociais e organizações da sociedade civil e nas manifestações culturais", enquanto que a educação escolar básica composta pela Educação Básica, formada pela educação infantil, ensino fundamental e ensino médio, tem como finalidade auxiliar os jovens na transição da infância à idade adulta e também assegurar-lhe a formação comum indispensável para o exercício da cidadania e fornecer-lhe meios para progredir no trabalho e em estudos posteriores.

A LDB também orienta-nos para uma educação que tenha como finalidade um desenvolvimento integral do nosso alunado, ou seja, uma educação que possibilite o desenvolvimento de valores afetivos, familiares, do pensamento, da educação emocional, das relações humanas, do uso racional de tecnologias de informação e do desenvolvimento sustentável. Além de prepará-los para a vida profissional, temos de auxiliá-los em seu processo de maturação, ou seja, no conjunto de processos neuropsicológicos que o jovem atravessa para adquirir a aprendizagem da linguagem, compreensão de si, do outro e do mundo.

Atualmente, vivemos num mundo caracterizado por uma busca incessante de respostas para os mais diversos problemas que surgem cotidianamente em nossas vidas. Perguntas que requerem respostas rápidas, práticas e úteis. E, como não poderia ser diferente em relação ao 
ensino de filosofia, apresentamos uma proposta de hermenêutica que o professor de Filosofia possa, juntamente com os alunos de o Ensino Médio equacionar as dificuldades em interpretar os textos de Filosofia que são estudados em sala de aula.

Para nós, professores, que estamos com a responsabilidade de lecionar a disciplina de Filosofia nas escolas deste nosso país, temos que pensar e re-pensar seriamente em como afetar nossos alunos, transformando nossas aulas de Filosofia em acontecimento. Acontecimento este que consiste numa apropriação da proposta de mundo apresentada pelo texto.

Ciente do contexto em que vivemos e da complexidade que envolve o ensino de filosofia para os jovens aqui em nosso país, há de ser levada em conta que nossa cultura não possui o hábito de leitura de livros. E, a maioria de nossos jovens mal sabe realizar uma interpretação textual. Segundo estimativas de um relatório sobre a crise da aprendizagem produzido pelo Banco Mundial com dados do Programa Internacional de Avaliação de Alunos (Pisa) $)^{3}$, alunos brasileiros vão demorar 260 anos para atingir índice de leitura dos países ricos. Então, o que fazermos para mudarmos esta situação?

Diante da situação em que se encontra nossa educação, entendemos a urgência de oferecermos condições educativas que auxiliem o alunado a ser eles mesmos, a não estarem submetidos à formação de um aluno ideal que não condiz com a realidade deles. Os alunos precisam alcançar sua conquista de pensamento autônomo, no qual possam estar abertos a se reeducarem, conscientes das escolhas e critérios de suas ações, assumindo a responsabilidades por suas consequências.

É comum alunos do Ensino Médio se queixarem dos textos filosóficos que lhe são apresentados em sala de aula. Segundo eles, os textos não apresentam sentido para a realidade em que eles se encontram, classificando-o como abstrato demais para ser entendido. Daí entendemos ser oportuno oferece-lhes uma "ferramenta", neste caso, a hermenêutica, para os capacitarem a pensar de maneira lógica e, para isso, nada mais importante do que situaçõesproblemas (violência no lar, angústia, maltrato aos animais, fome, corrupção, desrespeito) confrontados aos textos filosóficos, pois estes foram respostas a perguntas intrigantes que os filósofos procuraram elucidar. Sendo assim, os alunos devem perceber que a disciplina de Filosofia não constitui apenas uma apresentação de textos sem nenhuma interconexão com a vida humana, mas, sim, um conjunto de códigos, conceitos e regras que possibilitam a comunicação de ideias, interpretando e modelando a realidade e a si mesmo.

\footnotetext{
${ }^{3}$ https://www.oecd.org/pisa/PISA-2015-Brazil-PRT.pdf
} 
Acreditamos que a educação tem como foco principal revolucionar e auxiliar os jovens a alcançar uma melhor qualidade de vida pessoal e social. Para tanto, se faz necessário à elaboração de instrumentos, de conhecimentos e ações que visem uma mediação para o reconhecimento do si, do outro e da sociedade em que estão inseridos. Esse reconhecimento do si tem como finalidade uma melhor compreensão de si mesmo, da formação de sua identidade e de sua maturidade.

Da experiência que adquirimos ao lecionarmos a disciplina de Filosofia, temos a convicção da importância da hermenêutica em auxiliar os alunos do Ensino Médio para a compreensão textual, da cultura, para a vivência humana em sociedade e, principalmente, a compreensão de si mesmo como forma de desenvolverem suas identidades como seres autônomos, criativos e críticos. Por estas razões procuramos delinear os traços de uma hermenêutica filosófica que proporcionasse não apenas regras de interpretação textual, mas de uma compreensão que possibilite a criação de parâmetros filosóficos para os alunos criarem e re-criarem a si mesmo e o mundo de forma original e autônoma.

Devido à sua condição de sociabilidade o homem compreende a si mesmo numa mediação reflexiva e interacionista com o mundo e com o outro. Essa mediação o conduz à fase adulta, descentralizando as fantasias ilusórias da infância para dar lugar a uma nova identidade. Essa transição tem lugar a partir da reflexão, da interpretação, da flexibilidade em adquirir novos sentidos e valores que o permita viver bem numa perspectiva ética.

$\mathrm{O}$ percurso tomado ao reconhecimento do si requer mediações que priorizem o humano, assim como, a humanidade nos outros. Essas mediações ocorrem, primeiramente, em relação àquele semelhante a mim, ou seja, o outro distinto de mim. Uns mais próximos outros mais distantes, alguns no anonimato, mas que contribuíram com seu legado nas ciências, nos livros, nas obras de arte, na música, nas instituições etc.

Partindo dessas mediações os educadores podem auxiliar seus alunos a realizarem um esforço reflexivo para que eles tomem consciência de si, possibilitando-os a alcançarem a fase adulta com perspectivas de realizarem seus projetos pessoais e sociais com responsabilidade diante de seu próprio agir, como bem disse Ricoeur (2014, p.186) "a visada da vida boa com e para outrem em instituições justas”.

\section{Por um ensino de Filosofia como experiência filosófica}

Uma das tarefas desafiadoras para o professor de Filosofia está em ele pensar 
filosoficamente como se dará o ensino de Filosofia na sala de aula. Sabemos que os documentos oficiais do MEC tem buscado auxiliar a atividade filosófica do professor em sala de aula. É importante ressaltar que segundo estes documentos, as aulas de Filosofia ficam restritas a uma apresentação linear da história da Filosofia e, também a temas que são retirados desta. Por estar configurado desta maneira, o ensino de Filosofia possibilita-nos condições de repensarmos nossa prática pedagógica de maneira que afete o alunado, transformando suas vidas.

Do exposto no parágrafo anterior, o professor de Filosofia em sua atividade profissional deve pensar: qual Filosofia ensinar? Que objetivos educacionais podemos atribuir à Filosofia? Como ensinar Filosofia? Dá-se aula de Filosofia ou filosofamos com os alunos? Mas, o que é Filosofia, o que é filosofar? Ambas, são opostas? O que pode o ensino de Filosofia? Qual sua especificidade? São esses questionamentos que põem em movimento o pensar filosoficamente o ensino de filosofia.

Quando se propõe um ensino de Filosofia como experiência filosófica, provavelmente alguém nos objetará: é possível tal ensino? O que se quer dizer com experiência filosófica? Com esta proposta de ensino dispensaremos mais de vinte e cinco séculos de história da Filosofia? Há um método específico para por em prática este ensino? Todas estas questões são pertinentes para que possamos dirimir nossos objetivos a ser alcançados com a disciplina de Filosofia no Ensino Médio.

Acreditamos que é possível tal ensino, pois à medida que os alunos forem adquirindo experiência através dos textos de Filosofia, eles adquirirão habilidades para desenvolvimento de suas personalidades. Para um ensino de Filosofia em qualquer instância da educação não podemos dispensar a história da Filosofia, pois ela constitui o suporte para um ensino efetivo. Pensamos que para o ensino de Filosofia cada professor desenvolve seu próprio método no decorrer de seu trabalho em sala de aula.

Nós professores de Filosofia estamos com a incumbência de prepararmos nossos jovens para serem educados, para compreenderem os valores, as regras, a importância da vivência em sociedade, para a inserção no mercado de trabalho e, não apenas isto, mas que eles possam reconstruir suas subjetividades, pois num mundo cada vez mais informatizado, com diversas informações sendo transmitida por variados meios de comunicação, a indústria cultural forma a consciência coletiva em nossa sociedade e cria uma identidade de indivíduos consumidores, impossibilitando, desta forma, uma autonomia do pensamento.

Diferentemente do que ocorre com animais, o homem não está submetido 
instintivamente ao mundo da natureza, pois o mundo humano é mais amplo e mais rico do que o do animal. Por ser animal symbolicum, ele constrói seu próprio universo simbólico, possibilitando-lhe entender, interpretar, articular, organizar e sintetizar sua própria experiência de estar no mundo. A capacidade da linguagem simbólica propiciou algo inusitado ao homem, ou seja, a capacidade de construir um "mundo simbólico", tais como: a religião, a ciência, a filosofia, as artes etc. Transcendendo o mundo natural mediante formas simbólicas, o homem realiza o mundo das construções humanas.

Se homem é este animal symbolicum que confere significados às coisas, ele também pode se reeducar, re-significar suas ações, criar novos conceitos, exercer um pensamento não só crítico, reflexivo, rigoroso, mas emancipativo daquilo que já está posto na sociedade em que ele está inserido. Desde o alvorecer da Filosofia na Grécia que o ser humano busca a verdade, a essência das coisas, busca entender seu lugar no universo. A Filosofia como disciplina do pensamento, capaz de criar conceitos e dar sentido as nossas ações, consideramo-la primordial para ser exercida com os jovens em nossos dias. Daí que concordamos com Aspis quando ela afirma que a:

Filosofia é crítica - produz análise e síntese de toda a cultura - e criação. Por meio do ensino de filosofia para jovens, podemos incentivá-los a pensar por si mesmos, ou seja, podemos introduzi-los na prática de determinados instrumentos que os levem a poder pensar de forma autônoma, autoconsciente, a pensar com abrangência, profundidade e clareza. Podemos colaborar com a destreza de seu pensamento em fazer análise, síntese e relações, pensamento aberto e ciente da sua dimensão histórica. Pensamento este que tece significado do mundo a partir de questões simples sobre problemas, como: o que é isto?; por que isto é assim?; por que pensamos que isto seja assim? (ASPIS, 2009, p. 14)

Entendemos que para haver experiência filosófica nas aulas de Filosofia urge a necessidade de que ao aluno seja oferecidas condições para que ele conquiste sua própria identidade, uma identidade singular, que seja responsável por suas escolhas, consciente de suas ações e aberto a reeducar-se.

Os professores de Filosofia anseiam que seus alunos sejam afetados pelo pensamento filosófico. E, para isto, Renata Aspis defende que o ensino de Filosofia não pode ficar restrito a "modos de pensar das filosofias e conceitos filosóficos e as condições históricas da criação desses conceitos", mas "deve transpassar, atravessar o corpo, de um lado a outro, como uma flecha". A Filosofia consiste não só num modo de pensar, mas em sentir, agir e desejar. Na história da Filosofia fica evidente que os filósofos elaboraram suas filosofias a medida em que foram envolvidos com algo que os incomodavam, ou seja, com um problema. 
A proposta para um ensino de filosofia comprometido com a ideia de que o aluno possa torna-se autônomo, criativo, produtivo não pode esperar por uma disposição natural para o pensar. Os alunos devem ser confrontados "com signos que os forcem a pensar". Por estes, eles podem desenvolver a possibilidade de pensar filosoficamente, ou seja, a inventar os possíveis. Dar o que pensar para os alunos parece ser a saída fundamental para uma aula de filosofia que preze pelo filosofar.

Aspis questiona: "O que pode um estudante?", “O que resta ao professor?”. Para o primeiro, ser afetado, mas como? Para o segundo, resta os signos, mas o que isto significa? Só mesmo inventando bons signos que gerem afetos que provoquem, que movam, que forcem o pensamento do alunado. Os mais diversos estudos sobre o ensino de Filosofia geralmente objetivam implementar alguns recursos didáticos com o intuito de facilitar a vida dos docentes. Ou seja, que se entende por "ensinar filosofia" e como se poderia transmitir algo cuja identificação é já um problema filosófico? A tarefa de ensinar filosofia consiste em uma série de tomada de decisões. Estas são intrinsicamente filosóficas que nortearão a elaboração de recursos convenientes e coerentes para tornar possível e significativa aquela tarefa.

\section{O papel do professor de Filosofia no Ensino Médio}

O que se espera no ensino de Filosofia no Ensino Médio é que docentes da referida disciplina tenham um protagonismo central, uma vez que eles não são meros transmissores de conhecimento, tampouco executores de receitas genéricas. Mas eles são filósofos e filósofas que podem criar e recriar suas próprias didáticas. Para os problemas práticos do ensino de Filosofia não há "soluções" prontas e acabadas, partimos do pressuposto de que são os próprios docentes quem mais estão aptos a estabelecer a intervenção e construção de soluções para o ensino de Filosofia. Pois só eles estão em condições de avaliar com exatidão todos os elementos intervenientes em cada situação pontual.

O que se espera dos docentes de Filosofia é que sua formação consista em uma constante autoformação, ou seja, esta pressuponha uma trans-formação de si. Por isso, é de fundamental importância refletirmos sobre questões referentes ao ensino de Filosofia e acompanhar o que cada um pensa ser pertinente ao percurso pessoal de sua própria autoformação.

Para a pergunta “que é ensinar filosofia?" não é possível darmos uma resposta se não estivermos situados numa concepção ou perspectiva filosófica. A mola propulsora de um 
ensino filosófico se faz mediante o filosofar, e este, por sua vez, consiste numa atividade que entrelaça o fazer filosofia com sua transmissão. Pois o filosofar está arraigado no saber realizar perguntas filosóficas.

$\mathrm{Na}$ inquietude de formular e reformular perguntas e buscar respostas para essas constitui o desejo de saber. Observando como os filósofos buscaram respostas para os problemas que os inquietavam, alunos e professores podem se apropriar tanto dos questionamentos quanto das respostas filosóficas que foram elaboradas por aqueles, para que possam também solucionar problemas semelhantes por eles vivenciados.

O que, então, caracteriza um questionamento como filosófico? O que o diferencia de outros tipos de questionamentos? A essas questões se responde dizendo que depende do tipo de resposta esperada por aquele que a formula. Ou seja, o que define o caráter de um questionar filosófico está fundamentalmente na intencionalidade de quem realiza a pergunta. Questões tais como: o “que é a vida?", o “que é o Universo?”, o "que é o homem?", o "que é a morte?’. Podem também ser respondida por outras perspectivas que não a filosófica.

A intencionalidade filosófica se caracteriza como aspiração ao saber, porque um saber sem supostos. No entanto, por um saber sem suposto não ser possível, o questionar filosófico é constante. $\mathrm{O}$ interrogar filosófico não inventa as suas questões ou seus problemas do nada. Pode-se dizer que o filósofo é um re-criador de problemas.

À Filosofia já foi atribuído o lugar privilegiado da sabedoria, considerada um dos picos da cultura humanista. $O$ filósofo trazia em si a imagem daquele que possuía a experiência e a sabedoria com a qual podia guiar sua vida e, de certa forma, auxiliar os que não se dedicavam aos cumes da sabedoria. A Filosofia parece não gozar dos créditos que lhe foram conferidos durante sua história, crédito, que foi assinado por diversos filósofos ilustres como Sócrates, Platão, Aristóteles, Agostinho, Tomás de Aquino, Descates, Kant, Hegel entre outros.

Para o desenvolvimento da experiência filosófica concorre o aluno como construto de si mesmo, auxiliado por seu professor. Mas como pode isto ser realizado em sala de aula? Para tanto, é de fundamental importância que eles desenvolvam habilidades, usem de tentativas, criem conceitos mediante situação vivenciada por eles, pois um dos objetivos da Filosofia é a de auxiliar o aluno pensar crítica, reflexiva e produtivamente, talvez isto não ocorra de outra maneira.

O professor de Filosofia não é um mero professor que transmite conteúdos da história da Filosofia, ele deve ser filósofo. As aulas de Filosofia são momentos oportunos para a 
produção filosófica e, não apenas na elaboração de textos, mas, sim, de uma filosofia viva, isto é, filosofando com o alunado. O professor de Filosofia proporciona em suas aulas um espaço de problematização compartilhado por seus alunos. Ele instiga a que os jovens sejam capazes não só de analisar a consistência de um argumento, ou mesmo a correção de um raciocínio, mas que eles possam desconfiar da naturalidade de saberes e práticas que se apresentam como naturais.

A experiência filosófica em sala de aula tem como finalidade impelir o aluno a filosofar. Essa experiência poderá afetar o alunado para que estes elaborem linhas de fugas para problemas concretos do seu dia a dia. Assim, é oportuno que eles aprendam a ler, a pensar, a escrever, a investigar, a dialogar filosoficamente. Renata Aspis é bem enfática ao dizer que:

As aulas de filosofia, como lugar de experiência filosófica, tem como objetivo oferecer critérios filosóficos para o aluno julgar a realidade por meio da prática do questionamento filosófico e da construção de conceitos, por meio do exercício da criatividade e avaliação filosóficas. Assim, além dos critérios e do modo de pensar da indústria, do consumismo ou da mídia, além dos critérios e do modo de pensar da tradição e da ciência, o aluno passará a dispor dos critérios e do modo de pensar da filosofia para compor seu pensamento de forma autônoma, pois autoconsciente e, portanto, metacognitivo. (ASPIS, 2004, p. 310).

O ensino e a aprendizagem da filosofia constituem dois momentos importantes do exercício e da atividade filosófica na sala de aula, pois através desta atividade busca-se criar, inventar, re-inventar e produzir novos saberes e ações que se configurem como uma experiência filosófica. A experiência do filosofar proporciona uma maior flexibilidade entre o pensar e o agir, tendo como finalidade a emancipação intelectual do aluno.

Por experiência do filosofar entendemos não apenas a reflexão, a compreensão e interpretação dos textos filosóficos, mas uma auto interpretação que o sujeito assume por sua educação, identidade/constituição de si. Por suas deliberações e avaliações de suas ações, ele caminha para aquilo que Aristóteles havia chamado de "viver bem"/ "vida boa" e Paul Ricoeur chamou de "a visada da vida boa com e para outrem em instituições justas".

\section{A interpretação textual como processo fundamental para o filosofar}

Neste tópico apresentaremos aquilo que pensamos ser de fundamental importância para auxiliar nossos alunos em sua atividade filosófica, que é a capacidade de interpretação 
textual. Quando falamos sobre o ensinar filosofia e filosofar, a interpretação surge como algo necessário para o desenvolvimento deste processo.

É de suma importância que os textos, sejam eles filosóficos, teológicos, mitológicos, literários, retratem a experiência por eles representada. Se quisermos penetrar no mundo vivo do texto devemos:

Arriscar o nosso «mundo» pessoal se queremos penetrar no mundo vivo de um grande poema lírico, de um romance ou de uma obra. E para isso, não precisamos de qualquer método científico disfarçado, ou de qualquer «anatomia de uma crítica», com tipologias e classificações muito brilhantes e subtis, mas sim de uma compreensão humanística daquilo que implica a interpretação de uma obra. (PALMER, 1969, p. 19)

Ainda que se queira utilizar os métodos de «análise científica» para interpretação textual, devemos lembrar que os textos não são objetos da natureza bruta, mas produto de uma mente. O texto mostra-se como obra de homem, ela é uma "obra" e não um "objeto" manipulável conforme nas ciências naturais. Daí a importância de uma hermenêutica reflexiva que busque a "decifração", a "compreensão" de uma obra.

Independentemente da classe social, os seres humanos estão a utilizar da interpretação no seu dia a dia. O jornalista além de trazer as notícias ele as interpreta; o tradutor de língua estrangeira também de certa forma faz uma "interpretação"; o cientista interpreta a análise dos dados; em nossa vida diária interpretamos gestos, placas de trânsito, símbolos religiosos, enfim, "a interpretação é, portanto, talvez o ato essencial do pensamento humano; na verdade, o próprio facto de existir pode ser considerado como um processo constante de interpretação" (PALMER, 1969, p. 20).

Vivendo em sociedade o homem manifesta seus desejos e anseios por meio da linguagem. Por ela os seres humanos tecem suas relações sociais, culturais, religiosas. A linguagem é dinâmica, flexível, possui um poder incrível de comunicação. Por ela o homem molda seu mundo, seu pensamento e a si mesmo. Razão pela qual Palmer afirma que:

Muito mais do que pensa, o homem veicula através da linguagem as várias facetas da sua vida - aquilo que venera, aquilo que ama, os comportamentos sociais, o pensamento abstrato; mesmo a forma dos seus sentimentos é conforme com a linguagem. Se considerarmos este tema em profundidade, torna-se visível que a linguagem é o «medium» no qual vivemos, nos movemos e no qual temos o nosso ser (PALMER, 1969, p.21)

Talvez uma "falha" da objetividade moderna é a de encarar a obra como um «objeto» 
mais do que como «obra», o que distancia o leitor relativamente do texto; contudo, a finalidade da interpretação literária é ultrapassar a distância que o leitor está do texto. Não basta conhecer uma obra do mesmo modo que um psicanalista conhece os problemas do seu paciente; a interpretação literária deveria permitir que o evento linguístico captasse, dominasse e transformasse o próprio intérprete.

Compreendemos não ser possível dissociar filosofia do filosofar, não podemos separa o produto do seu processo. Para um ensino de filosofia que em sua proposta esteja o afetar o aluno, não pode ficar na passividade de ensinar matéria morta. É de suma importância que os alunos possam estar capacitados a apropriar conceitos filosóficos ou mesmo, se possível, a recriar estes conceitos. E, isso pode ser realizado mediante a filosofia e o filosofar. No entanto, não esqueçamos que para o alunado realizar esta tarefa se faz necessário que ele saiba interpretar.

É bem conhecida a clássica questão sobre a distinção entre filosofia e filosofar. Sobre isso Kant já assegurava não ser possível ensinar filosofia, devido ela não se constituir num saber fechado, mas que continua sempre aberto a novas possibilidades, sempre em movimento, nunca acabado. Por isso, “Até então não se pode aprender nenhuma filosofia; pois onde está ela? Quem a possui? Por que caracteres se pode conhecer? Pode-se apenas aprender a filosofar, isto é, a exercer o talento da razão na aplicação dos seus princípios gerais" [...] (Kant, 2001, p. 673). Para Kant, o máximo que podemos fazer é filosofar. O ato de filosofar para ele tornaria o indivíduo autônomo em seu exercício de análise e interpretação dos sistemas filosóficos.

Para aprender a filosofar deve ser estabelecido um diálogo crítico com a Filosofia. E, para que haja esse diálogo, se faz necessário "exercer o talento da razão na aplicação dos seus princípios gerais" para compreender e criticar os sistemas filosóficos. Mas para que os jovens alunos do Ensino Médio compreendam e critiquem não só sistemas de filosofia, como quaisquer outros tipos de texto, seja de poesia, jornalístico, ficcional, autobiográfico, etc., é importante que saibam não apenas lê-los, porém saibam interpretá-los. Pois do contrário acabam se tornando analfabetos funcionais, no qual sabem ler (decodificar palavras), mas não processam e não refletem sobre a informação recebida.

$\mathrm{Na}$ contramão da concepção kantiana de que não é possível ensinar filosofia, mas apenas filosofar, temos a posição de Hegel ao afirmar que no momento em que se conhece o conteúdo da filosofia já estamos filosofando. Para ele, não é possível filosofar sem ensinar a filosofia. As duas estão imbricadas uma na outra. Numa sociedade que nos induz a um 
consumismo desenfreado, não podemos "consumir" o conteúdo filosófico, mas fazer dele, e aqui concordamos com Renata Aspis, devemos "ler filosofia como se lê poesia, revivendo-a: ressuscitando-a, encarnando-a, emocionando-se com ela, reinventando-a”.

Mediante o ensino de Filosofia no Ensino Básico da Educação percebemos a possibilidade de os alunos construírem e fundamentarem suas ações pautadas numa mediação do si e do outro. Para tanto, urgia a importância de uma Filosofia reflexiva que oferecesse os fundamentos para reavaliar as práticas educativas para consolidação dos projetos educativos. A partir deste contexto, vimos à contribuição que o filósofo Paul Ricoeur (1913-2005) poderia nos auxiliar para realizarmos uma tarefa de "reflexão concreta" da educação e da formação de identidade dos jovens.

Autor de vastíssimas obras, Paul Ricoeur é sem dúvida um dos mais importantes pensadores do século XX. O pensador francês dialoga com os mais variados campos do conhecimento, tais como: a filosofia reflexiva, a fenomenologia, o existencialismo, a filosofia analítica, a hermenêutica, entre outras. Sua proposta hermenêutica consiste em que esta seja tomada não apenas como um guia metodológico para interpretações textuais, mas pressupondo uma atitude ontológica e reflexiva. Para Paul Ricoeur o problema da compreensão hermenêutica, só é possível por mediação dos outros (que pode ser um texto ou mesmo os outros homens). Ao dar-se conta de sua existência, o ser humano quer viver a vida e não somente que ela passe por ele. Busca uma vivência construída na relação com o mundo e com os outros, pois nesta contínua dialética de inter-relação com o mundo e com os outros, compreenderemos a nós mesmos.

O projeto filosófico riccoeuriano consiste em mostrar que toda a filosofia é hermenêutica, e o que isto que dizer? Que toda a sua preocupação está centrada numa preocupação antropológica, ou seja, busca-se compreender o homem, quem ele é, sua historicidade, sua atuação no mundo. É necessário ressaltar que a hermenêutica proposta por Paul Ricoeur não consiste apenas na procura e apropriação do sentido nos textos, mas numa apropriação de compreensão de nós mesmos e do mundo em que estamos inseridos. $\mathrm{O}$ trabalho interpretativo proposto por esta hermenêutica antropológica permite-nos vencer as distâncias e as diferenças culturais, unindo os horizontes do leitor/intérprete com o texto, do qual este se lhe tornou estranho.

O homem desde sua origem está inserido numa determinada realidade, para compreender-se faz-se necessário compreender a partir do seu estar no mundo. Por ser um sujeito simbólico, necessita ser interpretado para melhor dizer sobre si mesmo a outrem. Para 
compreender-se como sujeito capaz de agir no mundo, ele busca entender este seu agir e, para tal, utilizar-se-á de uma linguagem simbólica.

Ao tornar-se um ser de possibilidade, o sujeito compreende-se-á como um ser responsável por seu agir e, de interpretar a realidade em que está inserido. Desta forma, surge a necessidade de uma capacidade reflexiva, capaz de interpretar a realidade e a si mesmo. Se o ser humano é um ser de ação no mundo, como podem os alunos do Ensino Médio ordenar e reconstruir suas experiências vividas, tornando-se sujeito de uma possível compreensão de si mesmo e do mundo em que vivem? De que forma podem eles ser capazes de interpretar o seu próprio eu? De que maneira o componente narrativo de autocompreensão contribui para um autoexame na vida real?

O problema da hermenêutica, segundo Ricouer, está vinculado diretamente ao problema de interpretação. Para ele há duas vias deste problema: a primeira está relacionada ao campo de aplicação dos textos. Estes possuem autonomia em relação às intenções do seu autor, assim como, da situação da obra e possibilita um amplo público de leitores. O texto não possui um caráter dialogal como acontece no discurso oral. Por esta razão, o texto necessita, pede para ser interpretado. A centralidade no texto é de suma importância para a concepção hermenêutica de Ricouer, pois esta dá um passo de uma hermenêutica como interpretação dos símbolos para uma hermenêutica como interpretação dos textos.

Uma segunda via tem relação com o problema epistemológico da interpretação. Esta interpretação constitui um conceito oposto ao de explicação, pois a interpretação tem conotações subjetivas, em que há uma implicação do leitor no processo de compreensão e reciprocidade entre interpretação do texto e interpretação de si mesmo. Desta forma, o problema da hermenêutica está posto entre dois polos: o primeiro trata-se do estatuto de textos contraposto a linguagem oral; o segundo estatuto tem vinculação a interpretação contraposto ao de explicação. Paul Ricouer dedicou várias de suas obras a exposição de sua abordagem hermenêutica como interpretação de textos, abordagem esta que está estritamente vinculada as análises relativas à metáfora. Razão pela qual ela faz um percurso entre a metáfora e o texto, mas isto com a noção de discurso.

De acordo com Ricouer, o discurso possui algumas propriedades intrínsecas que podem ser classificadas como: 1) o discurso constitui-se em um acontecimento, pois este aparece e desaparece; sua existência é fugaz, porém pode ser identificado e reidentificado ele mesmo possuindo um significado. 2) A significação possui uma estrutura específica a proposição que envolve uma oposição interna entre um polo de identificação singular e de 
predicação geral. 3) $\mathrm{O}$ discurso à semelhança da frase tem uma polaridade entre sentido e referência, pois aquilo que é dito pela frase como um todo e, também pelas palavras referemse a alguma coisa quando algo é dito (falar é dizer algo sobre algo). 4) O discurso implica em um ato de conteúdo proposicional, ou dito de outra maneira, é a "força" do ato completo do discurso. No discurso, além do ato proposicional, tem o ato locucionário (o que é dito do sujeito) e o ato ilocucionário (o que eu realizo ao dizer). 5) Para finalizar, o discurso possui três classes de referência: a) remete a uma realidade extralinguística, b) a seu interlocutor e, c) ao que se designa o discurso. Uma estrutura que se designa por: "eu", "tu", "ele". No discurso tem-se uma referência à realidade e uma referência aos interlocutores.

Do exposto no parágrafo anterior, fica evidente que o discurso mantém duas perspectivas: a primeira, que é o discurso enquanto evento, ou seja, é algo que sucede quando alguém fala, é a instância do discurso. A segunda, diz respeito ao discurso enquanto significação, pois diz algo sobre algo. Tanto evento quanto a significação constituem os polos de uma dialética pela qual é possível alcançarmos uma noção acabada de discurso. De um lado, o discurso é efetuado como evento, de outro, é compreendido como significação.

Em sendo assim, o discurso constitui o terreno comum para a teoria da metáfora e para a teoria do texto. Este pode ser específico de uma frase até ir a "obras" maiores. Por sua vez, a metáfora possui uma extensão mínima na palavra, contudo, a metáfora exige determinados contexto que a façam funcionar. Quando a metáfora cumpre sua função, fala-se em "enunciados metafóricos". Desta forma, ela passa a ser considerada como uma "obra em miniatura" por cumprir as propriedades do discurso.

A relação entre metáfora e texto se sustenta à medida que a compreensão da metáfora (a partir de uma perspectiva da explicação, a qual se refere ao sentido, ou seja, ao plano imanente ao discurso) auxilia-nos na compreensão de textos mais longos. A compreensão de uma obra em sua totalidade fornece a chave para uma metáfora, e, isto, desde uma perspectiva da interpretação, que promove outro aspecto da significação que é a referência. A partir da relação metáfora e texto, ela constitui uma direção intencional para um mundo e para um si mesmo. A metáfora estabelece uma conotação potencial, ela transforma uma propriedade atual ou atribuída em sentido. Assim diz Ricouer em sua obra Hermenêutica e ação:

As metáforas ao requerer de um contexto (linguístico, cultural, semântico) torna-se em atos. De um modo especial nas metáforas que carregam a inovação de uma significação emergente: a metáfora viva que é acontecimento e sentido ao ser considerada como nova criação linguística. Por outro lado a metáfora se diz de um "sujeito principal", de tal maneira 
que a identificação singular e a predicação geral se fazem presentes como ação contextual quanto que a metáfora é "modificador" do dito sujeito operando como uma atribuição deste (RICOUER, 2008, p. 38).

A metáfora nova consiste em uma criação momentânea da linguagem, ela é uma inovação semântica que não possui estatuto, pois é possível falar de inovação semântica como uma significação suscetível de ser identificada e reidentificada unicamente levando em consideração o ponto de vista do autor ou do leitor e tratar a novidade emergente como contrapartida da parte do autor, de uma construção da parte do leitor.

As palavras adquirem sentido mediante a interseção entre vários campos semântico, mas a "torção metafórica" por sua vez é acontecimento e uma significação. Para Ricouer, isto constitui uma categoria fundamental que faz da metáfora um paradigma para explicação da obra literária. Desta forma, isso torna possível construir a significação de um texto de maneira semelhante aquela pela qual produzimos sentido com todos os termos de um enunciado metafórico.

Realizando o percurso inverso, indo do texto para a metáfora aquele está marcado pela interpretação. A compreensão do texto torna-se a chave fundamental para a compreensão da metáfora, pois algumas categorias do discurso somente surgem na medida em que quando este toma forma de obra literária, ou seja, quando possui referência e autorreferência. A situação torna-se complicada à medida que o discurso provém do texto, pois este, diferentemente da linguagem falada, não possui uma situação comum entre os interlocutores. Não é possível a mostração, o apontar com o dedo. Na linguagem escrita à referência já não é ostensiva. Se fala das coisas, de estado de coisas, de acontecimentos que ali não estão. Os textos literários, por sua vez, propõe um mundo, que é o mundo desta obra. A este mundo se refere Ricouer ao dizer que é aqui que o homem tem um mundo e não somente uma situação. O mundo como conjunto de referências abertas pelos textos.

A referência do texto implica dizer que sua significação não esteja por trás do texto senão diante dele. Aponta para um mundo possível, a maneiras possíveis de se orientar nesses mundos. Sendo assim, o trabalho interpretativo consiste em apropriar-se das proposições de mundo possibilitadas pelas referências não ostensivas do texto. À interpretação textual o papel da subjetividade não pode ser descrito como uma projeção, mas, sim, de um compreender-se ante a obra. É deixar-se ser conduzido pela obra e pelo mundo que esta propõe para que ampliem o horizonte de compreensão que temos de nós mesmos. De acordo com a proposta riccoeriana, a interpretação consiste no processo pelo qual o descobrimento de novos modos 
de ser dá ao sujeito uma nova capacidade de conhecer-se a si mesmo. Desta forma, nos diz Ricoeur:

\begin{abstract}
A hermenêutica não submete a interpretação às capacidades finitas da compreensão de um leitor dado; não põe a significação do texto sob o poder do sujeito que o interpreta. Longe de dizer que um sujeito domina já sua forma de ser no mundo e a projeta como o a priori de sua leitura, diríamos que a interpretação é o processo pelo o qual o descobrimento de novos modos de ser - ou, se se prefere Wittgenstein a Heidegger, novas "formas de vida" - dá ao sujeito uma nova capacidade de conhecer-se a si mesmo. Se há em algum ponto projeto e projeção, é a referência da obra que é o projeto de mundo. O leitor é em consequência engrandecido em sua capacidade de projetar-se a si mesmo recebendo do texto um novo modo de ser (RICOUER, 2008, p. 38).
\end{abstract}

A nova proposta de hermenêutica não significa que a interpretação consista em entrar num via de sentido único, sendo determinado unicamente pelo intérprete, como se toda a atividade proviesse deste. $\mathrm{O}$ intérprete deve guiar-se pelo texto e ir até aonde o texto queira conduzi-lo. Desta forma, interpretar tem como finalidade, discernir o discurso da obra, o qual é uma palavra temporalizada com referência a um mundo e aos interlocutores.

A teoria ricoeuriana de hermenêutica, no que diz respeito ao trabalho de interpretação, estimula, promove e provoca uma imaginação crítica por suas propostas de mundo abertas com suas referências não ostensivas. Tanto a hermenêutica do símbolo, da metáfora quanto a do texto possibilita-nos imaginar, pensar e articular várias propostas de mundo.

Os textos de ficção e poéticos possibilitam dizer algo sobre o mundo, assim como, redescrever-lo. Ao suspender a referência ostensiva e descritiva do mundo, a metáfora libera um poder de referência que não podia ser descrito diretamente. A hermenêutica de Ricouer possui um caráter provocativo, subversivo e criativo de novas possibilidades para o nosso ser no mundo.

\title{
Considerações finais
}

Nossa reflexão a partir dos textos riccoerianos levou-nos a compreender, a ressaltar e a resgatar o sentido de uma hermenêutica do si como forma de os alunos alcançarem sentido para as esferas do ser, do ter, do valor e do poder. Como manifestações próprias do ser humano. Essas esferas proporciona-nos compreender nossas limitações, assim como nossos valores e ideais como esforço por existir e o desejo de ser. 
Ao buscarmos uma interpretação para nossa existência, entendemos a importância da consciência, não como ponto de partida, mas como ponto de chegada. Essa postura nos remete para aquilo que Ricoeur chama de consciência como tarefa. Perfazendo o percurso tomado por este autor em sua obra, Do texto à ação, visualizamos a importância do texto como mediação reflexiva para uma hermenêutica do si.

Para isso, percebemos a necessidade de compreendermos o alcance da ideia de "mundo do texto" e sua relevância para uma educação que pretende uma formação do homem em todas as dimensões. Essa mediação de "mundo de texto" e o mundo do leitor oferece-nos o percurso para uma melhor compreensão do si. A hermenêutica do si-mesmo possibilitada por essa mediação leva-nos a reconhecer nossa identidade e nossa atuação no mundo e com o outro. O símbolo, o texto, o outro, a narração são as mediações que possibilitam a constituição de nossa identidade e é por elas que podemos chegar ao si mesmo como outro.

Nos dias de hoje urge a necessidade de um ensino de Filosofia que preze por um profissional que potencialize a vida, que proporcione ao alunado competências para reexistirem. Para Renata Aspis, "essa guerrilha é travada no micro, cada aula, cada avaliação, cada texto, cada tática pedagógica, cada conceito: micropolítica de um ensino de filosofia possível. Tem de ser inventado, renovadamente, insistentemente, re-existir".

Como havíamos dito acima, não há uma "receita" (método) eficaz de se ensinar filosofia. A "didática" da filosofia consiste em uma construção contínua entre teoria e prática sobre uma base conceitual que deverá ser atualizada constantemente. É de suma importância que cada professor-filósofo e professora-filósofa tenham uma posição clara entre o filosofar e seu ensino. Podemos perceber que o "como" ensinar filosofia está intrinsicamente ligada à concepção que se tenha de filosofia e do filosofar.

O ensino e a aprendizagem da Filosofia constituem dois momentos importantes do exercício e da atividade filosófica na sala de aula. Pois através desta atividade buscar-se-á criar, inventar, reinventar e produzir novos saberes e ações que se configurem como uma experiência filosófica. A experiência do filosofar possibilita uma maior flexibilidade entre o pensar e o agir, tendo como finalidade a constituição do si do alunado. Mediante a experiência do filosofar entendemos não apenas a reflexão, a compreensão e interpretação dos textos filosóficos, mas uma auto interpretação que o sujeito assume por sua educação, identidade/constituição de si.

Por suas deliberações e avaliações de suas ações, o aluno caminha para aquilo que Paul Ricoeur chamou de "a visada da vida boa com e para outrem em instituições justas". E 
para alcançar essa "vida boa com e para outrem em instituições justas" parece necessário à capacidade de ordenar e reconstruir suas experiências de vida. Para alcance desse objetivo o sujeito tem de interpretar o seu próprio eu. Pois o ser humano busca não só fazer uma descrição de sua existência no mundo, ele quer interpretar o sentido desta sua existência, razão pela qual possui uma necessidade de compreender o seu ser mundo. Realizando esse esforço reflexivo para uma tomada da consciência de si, os alunos podem adquirir novos sentidos e valores que o permitam viver numa perspectiva ética, possibilitando-os desenvolver seus projetos pessoais e sociais com responsabilidade diante de seu próprio agir.

Nessa trajetória de uma hermenêutica do si como uma compreensão do si para a constituição deste mesmo si, nos leva para um âmbito importante da vida humana, que é a da ética. Conforme já dissemos acima de acordo com as palavras de Paul Ricoeur, o alcance e a relevância de encontrarmos "a visada da vida boa com e para outrem em instituições justas" são indispensáveis para uma educação que pretenda ser o suporte para formar o cidadão, para que este seja uma pessoa autônoma, solícita e responsável por seus atos.

Os alunos mediante suas deliberações podem desenvolver e alcançar a virtude do homem sábio e prudente. Pode inventar condutas apropriadas para as mais diversas situações do seu dia a dia, conquistando, desta forma, a "sabedoria prática" para a superação dos eventuais conflitos em si e, com o diverso de si. A experiência do filosofar que entendemos ser posta em prática com os alunos do Ensino Médio busca afetá-los naquilo que pensamos ser mais importante para a vida do individuo, que são suas ações práticas.

\section{Referências}

ASPIS, Renata Lima. Ensinar filosofia: um livro para professores. $1^{a}$ Edição. Editora: Atta Mídia e Educação. São Paulo, 2009.

\section{.Fragmentos de ideias sobre ensino de filosofia e re-existência.}

O professor de filosofia: o ensino de filosofia no ensino médio como experiência filosofia. Cad. Cedes, Campinas, vol. 24, n. 64, p. 305-320, set./dez. 2004. Disponível em ,http://www.cedes.unicamp.br>

BRASIL: MEC/SEB: Lei de Diretrizes e Bases da Educação no Brasil. Disponível em: http://portal.mec.gov.br/arquivos/pdf/ldb.pdf. Acessado em 11 jan.2018.

PALMER, Richard E. Hermenêutica. Edições 70. - Lisboa, 1969.

Ricoeur, Paul. O si-mesmo como um outro. $1^{\text {a }}$ ed. Editora WMF Martins Fontes. - São Paulo, 2014

Hermenêutica e ação: da hermenêutica do texto a hermenêutica da ação. $1^{\text {a }}$ d. Prometeo Libros. - Buenos Aires, 2008. 
Teoria da interpretação: o discurso e o excesso de significação. Trad. por Artur Moão do original inglês Interpretation Theory: discourse and the surplus of meanig. Lisboa: Edições 70, 2000.

Del texto a la acción: ensayos de hermenêutica II. Tradução de Pablo Corona.Editora: Fondo de Cultura Económica. México, 2002. 